\title{
PULMONARY ARTERIOVENOUS FISTULA: UNCOMMON CAUSE OF STROKE IN YOUNG PATIENTS
}

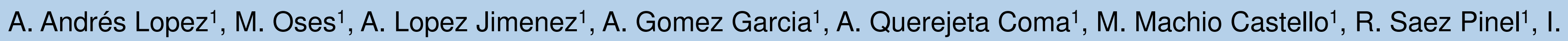 Zamarbide Capdepon'1, I. Navas Vinagre', M.A. García Torres¹.
${ }^{1}$ Fundación Jimenez Diaz, Neurology, Madrid, Spain. ${ }^{2}$

\section{Background and Aims}

- To describe an infrequent etiology of stroke in a 22-year-old male patient.

\section{Methods}

- Clinical case description.

\section{Results}

- A 22-year-old male who has a personal story of viral myopericarditis and familial adenomatous polyposis that was colectomized.

- He presented a sudden transient episode of 15 minutes of coordination deficit in the right limbs. Three hours later he suffered an episode of dysarthria, holocranial headache and gait instability for the next two hours.

- There were no signs of neurological deficit in the examination

- Cerebral MRI showed multiple acute ischemic lesions in both cerebellar hemispheres.

- The transesophageal echocardiogram showed patent oval foramen without interatrial septal aneurysm.
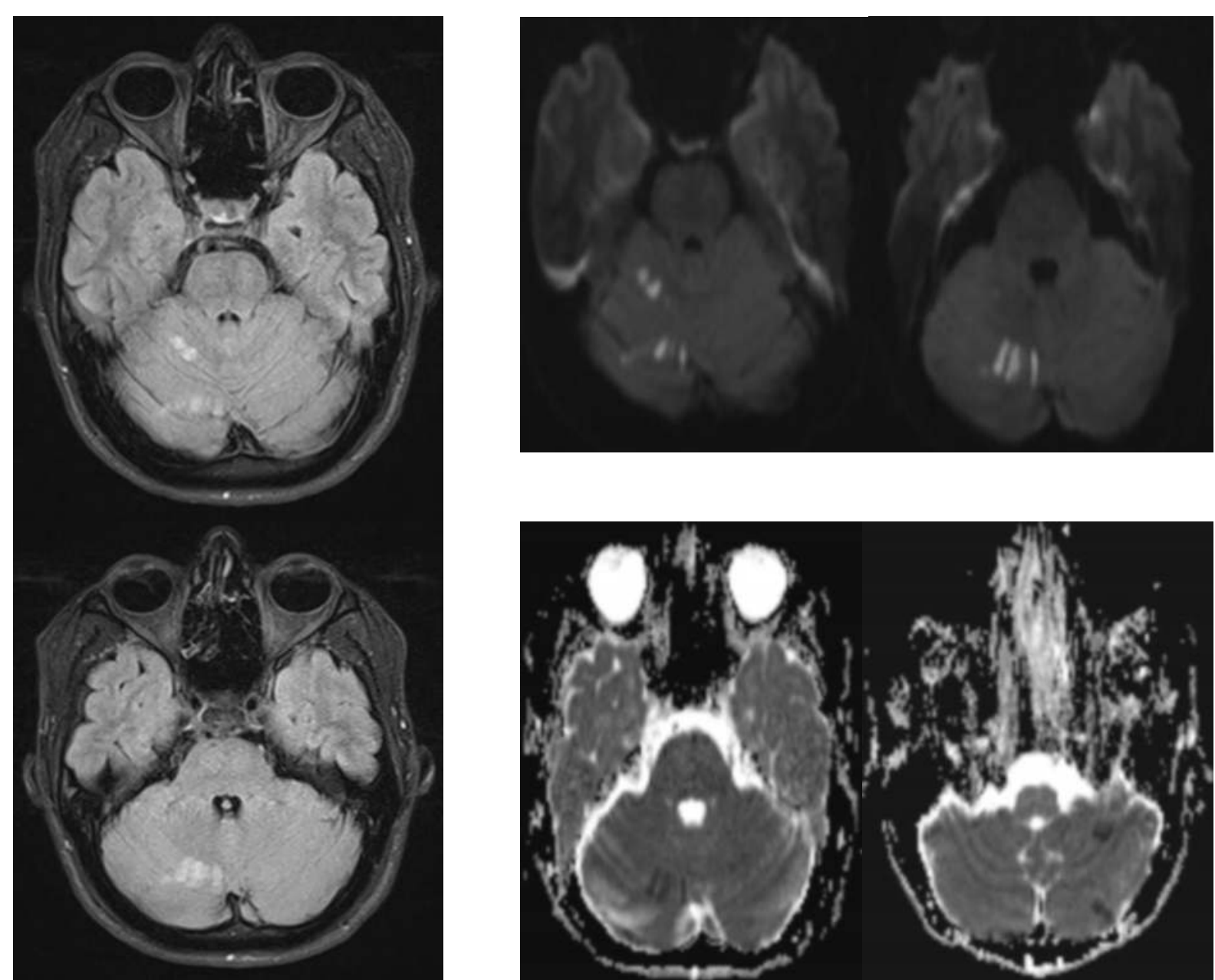

- The patient was heterozygous for the C677T mutation of the MTHFR gene

- A thoraco-abdominopelvic CT showed a $13 \mathrm{~mm}$ arteriovenous fistula in the lower lobe of the right lung.

- The rest of the complementary tests were normal.

- The patient was managed with embolization of the fistula without any complication and he remained asymptomatic.

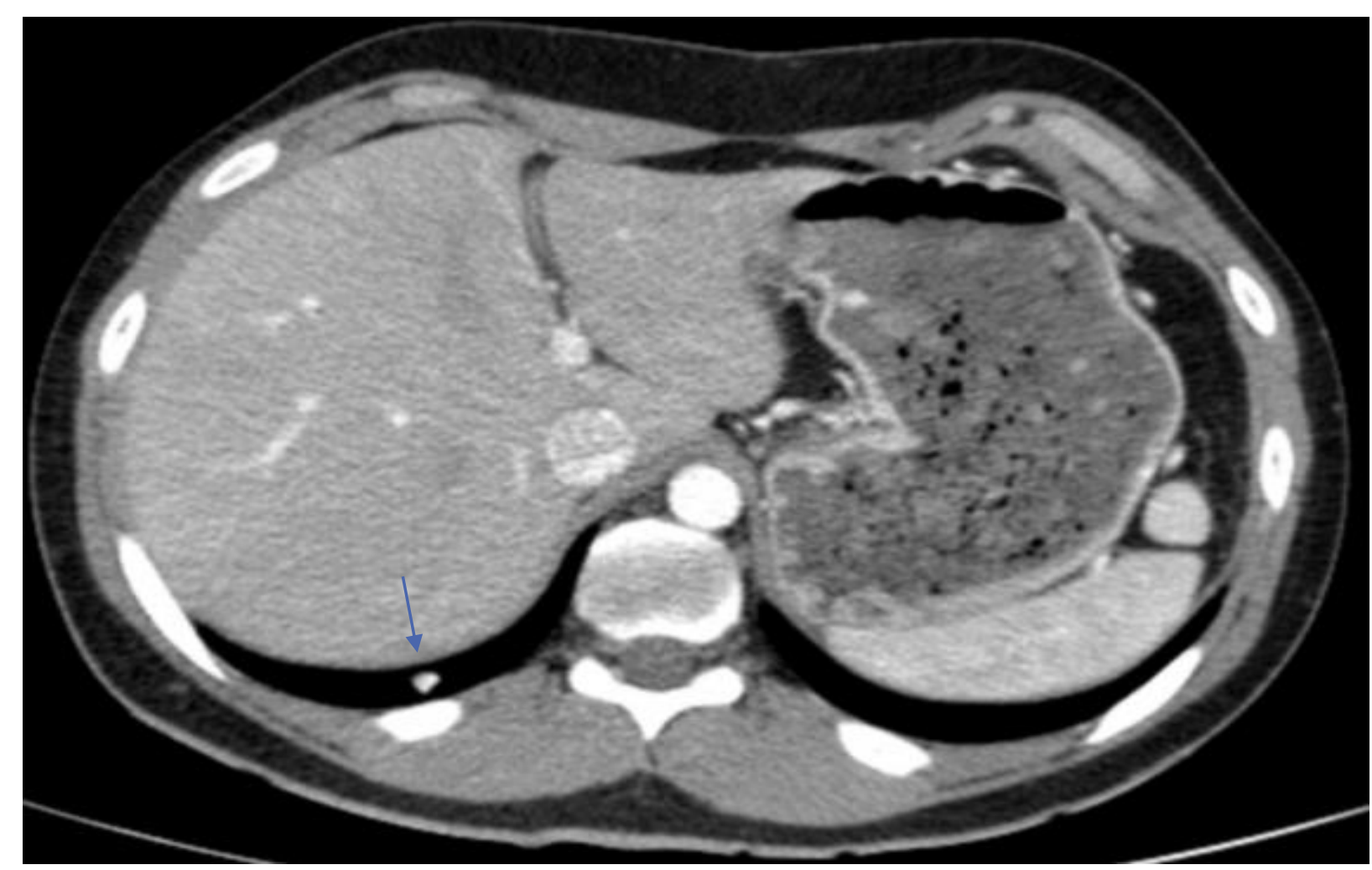

Conclusions

- Pulmonary arteriovenous fistulas are a rare cause of stroke in young patients.

- They must be taken into account in order to establish the etiology of stroke in young patients in which no other cause has been found.

- They are treatable lesions, so the stroke risk recurrence may be reduced in diagnosed and treated patients.

\section{Bibliography}

Maaijwee NA, Rutten-Jacobs LC, Schaapsmeerders P, van Dijk EJ, de Leeuw FE (2014) Ischaemic stroke in young adults: risk factors and long-term consequences. Nat Rev Neurol 10(6):315-325

Moussouttas M, Fayad P, Rosenblatt M, et al: Pulmonary arteriovenous malformations: cerebral ischemia and neurologic manifestations. Neurology 2000;55:959-964 